TI 2013-021/III

Tinbergen Institute Discussion Paper
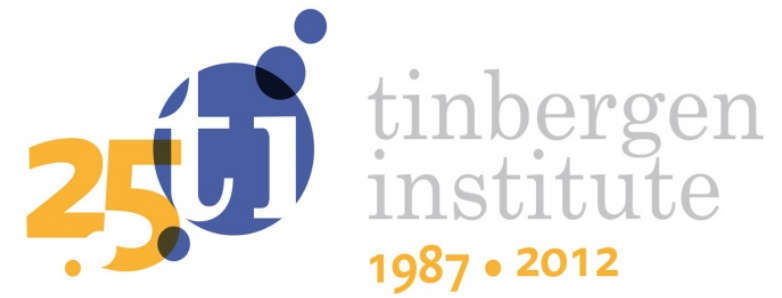

\title{
Recent Developments in Financial Economics and Econometrics:
}

\section{An Overview}

\author{
Chia-Lin Chang \\ David Allen ${ }^{2}$ \\ Michael McAleer ${ }^{3}$
}

' National Chung Hsing University, Taiwan;

2 Edith Cowan University, Australia;

3 Econometric Institute, Erasmus School of Economics, Erasmus University Rotterdam, Tinbergen Institute; Complutense University of Madrid, Spain; and Kyoto University, Japan. 
Tinbergen Institute is the graduate school and research institute in economics of Erasmus University Rotterdam, the University of Amsterdam and VU University Amsterdam.

More TI discussion papers can be downloaded at http://www.tinbergen.nl

Tinbergen Institute has two locations:

Tinbergen Institute Amsterdam

Gustav Mahlerplein 117

1082 MS Amsterdam

The Netherlands

Tel.: +31(0)205251600

Tinbergen Institute Rotterdam

Burg. Oudlaan 50

3062 PA Rotterdam

The Netherlands

Tel.: +31(0)10 4088900

Fax: $+31(0) 104089031$

Duisenberg school of finance is a collaboration of the Dutch financial sector and universities, with the ambition to support innovative research and offer top quality academic education in core areas of finance.

DSF research papers can be downloaded at: http://www.dsf.nl/

Duisenberg school of finance

Gustav Mahlerplein 117

1082 MS Amsterdam

The Netherlands

Tel.: +31(0)20 5258579 


\title{
Recent Developments in Financial Economics and Econometrics: An Overview*
}

\author{
Chia-Lin Chang \\ Department of Applied Economics \\ Department of Finance \\ National Chung Hsing University, Taiwan
}

\author{
David Allen \\ School of Accounting, Finance and Economics \\ Edith Cowan University, Australia \\ Michael McAleer \\ Econometric Institute \\ Erasmus School of Economics \\ Erasmus University Rotterdam \\ and \\ Tinbergen Institute \\ The Netherlands \\ and \\ Department of Quantitative Economics \\ Complutense University of Madrid, Spain \\ and \\ Institute of Economic Research \\ Kyoto University, Japan
}

January 2013

* The authors wish to thank the referees for their timely and helpful comments and suggestions on the papers comprising the special issue. For financial support, the first author wishes to thank the National Science Council, Taiwan, the second author acknowledges the Australian Research Council, and the third author is most grateful to the Australian Research Council, National Science Council, Taiwan, and the Japan Society for the Promotion of Science. 


\begin{abstract}
Research papers in empirical finance and financial econometrics are among the most widely cited, downloaded and viewed articles in the discipline of Finance. The special issue presents several papers by leading scholars in the field on "Recent Developments in Financial Economics and Econometrics". The breadth of coverage is substantial, and includes original research and comprehensive review papers on theoretical, empirical and numerical topics in Financial Economics and Econometrics by leading researchers in finance, financial economics, financial econometrics and financial statistics. The purpose of this special issue on "Recent Developments in Financial Economics and Econometrics" is to highlight several novel and significant developments in financial economics and financial econometrics, specifically dynamic price integration in the global gold market, a conditional single index model with local covariates for detecting and evaluating active management, whether the Basel Accord has improved risk management during the global financial crisis, the role of banking regulation in an economy under credit risk and liquidity shock, separating information maximum likelihood estimation of the integrated volatility and covariance with micro-market noise, stress testing correlation matrices for risk management, whether bank relationship matters for corporate risk taking, with evidence from listed firms in Taiwan, pricing options on stocks denominated in different currencies, with theory and illustrations, EVT and tail-risk modelling, with evidence from market indices and volatility series, the economics of data using simple model free volatility in a high frequency world, arbitrage-free implied volatility surfaces for options on single stock futures, the non-uniform pricing effect of employee stock options using quantile regression, nonlinear dynamics and recurrence plots for detecting financial crisis, how news sentiment impacts asset volatility, with evidence from long memory and regime-switching approaches, quantitative evaluation of contingent capital and its applications, high quantiles estimation with Quasi-PORT and DPOT, with an application to value-at-risk for financial variables, evaluating inflation targeting based on the distribution of inflation and inflation volatility, the size effects of volatility spillovers for firm performance and exchange rates in tourism, forecasting volatility with the realized range in the presence of noise and non-trading, using CARRX models to study factors affecting the volatilities of Asian equity markets, deciphering the Libor and Euribor spreads during the subprime crisis, information transmission between sovereign debt CDS and other financial factors for Latin America, time-varying mixture GARCH models and asymmetric volatility, and diagnostic checking for non-stationary ARMA models with an application to financial data.
\end{abstract}

Keywords: Dynamic price integration, local covariates, risk management, global financial crisis, credit risk, liquidity shock, micro-market noise, corporate risk taking, options, volatility, quantiles, news sentiment, contingent capital, value-at-risk, inflation targeting, size effects, exchange rates, realized range, equity markets, sub-prime crisis, sovereign debt CDS, mixture models, asymmetry, diagnostic checking..

JEL: G11, G12, G13, G15, G18. 


\section{Introduction}

Based on citations in Thomson Reuters ISI, Google Scholar, Microsoft Academic Search, RePEc (Research Papers in Economics and Finance), and paper downloads and abstract views in SSRN (Social Science Research Network) and RePEc, research papers in empirical finance and financial econometrics are among the most widely cited, downloaded and viewed articles in the discipline of Finance. The special issue will present several papers by leading scholars in the field on "Recent Developments in Financial Economics and Econometrics". The breadth of coverage is substantial, and includes original research and comprehensive review papers on theoretical, empirical and numerical topics in Financial Economics and Econometrics by leading researchers in finance, financial economics, financial econometrics and financial statistics.

The purpose of this special issue on "Recent Developments in Financial Economics and Econometrics" is to highlight several novel and significant developments in financial economics and financial econometrics, specifically dynamic price integration in the global gold market (Chang, Chang and Huang, 2013), a conditional single index model with local covariates for detecting and evaluating active management (Caporin and Lisi, 2013), whether the Basel Accord has improved risk management during the global financial crisis (McAleer, Jiménez-Martín and Pérez-Amaral, 2013), the role of banking regulation in an economy under credit risk and liquidity shock (Soares da Silva and Divino, 2013), separating information maximum likelihood estimation of the integrated volatility and covariance with micro-market noise (Kunitomo and Sato, 2013), stress testing correlation matrices for risk management (So, Wong and Asai, 2013), whether bank relationship matters for corporate risk taking, with evidence from listed firms in Taiwan (Chan, Lin, Chang and Liao, 2013), pricing options on stocks denominated in different currencies, with theory and illustrations (Ng, Li and Chan, 2013), EVT and tail-risk modelling, with evidence from market indices and volatility series (Allen, Singh and Powell, 2013), the economics of data using simple model free volatility in a high frequency world (Garvey and Gallagher, 2013), arbitrage-free implied volatility surfaces for options on single stock futures (Kotze, Labuschagne, Nair and Padayachi, 2013), the non-uniform pricing effect of employee stock options using quantile regression (Kuo and Yu, 2013), nonlinear dynamics and recurrence 
plots for detecting financial crisis (Addo, Billio and Guegan, 2013), how news sentiment impacts asset volatility, with evidence from long memory and regime-switching approaches (Ho, Shi and Zhang, 2013), quantitative evaluation of contingent capital and its applications (Gupta, Akuzawa and Nishiyama, 2013), high quantiles estimation with Quasi-PORT and DPOT, with an application to value-at-risk for financial variables (Araujo Santos, Fraga Alves and Hammoudeh, 2013), evaluating inflation targeting based on the distribution of inflation and inflation volatility (Ginindza and Maasoumi, 2013), whether there are size effects of volatility spillovers for firm performance and exchange rates in tourism (Chang, Hsu and McAleer, 2013), forecasting volatility with the realized range in the presence of noise and non-trading (Bannouh, Martens and van Dijk, 2013), using CARRX models to study factors affecting the volatilities of Asian equity markets (Sin, 2013), deciphering the Libor and Euribor spreads during the subprime crisis (Pelizzon and Sartore, 2013), information transmission between sovereign debt CDS and other financial factors for Latin America (Wang, Yang and Yang, 2013), time-varying mixture GARCH models and asymmetric volatility (Haas, Krause, Paolella and Steude, 2013), and diagnostic checking for non-stationary ARMA models with an application to financial data (Ling, Zhu and Yee, 2013).

The remainder of the paper is organized as follows. An overview of the papers is given in Section 2, while Section 3 provides some concluding comments.

\section{Overview}

In the first paper, "Dynamic price integration in the global gold market", Chia-Lin Chang (National Chung Hsing University, Taiwan), Jui-Chuan Della Chang (National Chiayi University, Taiwan) and Yi-Wei Huang (National Chung Hsing University, Taiwan) examine the inter-relationships among gold prices in five global gold markets, namely London, New York, Japan, Hong Kong (since 1 July 1997, a Special Administrative Region (SAR) of China), and Taiwan. The authors investigate the linkages between Taiwan and the other global gold markets to provide insights for useful investment strategies. The augmenting level-VAR models show that the empirical results find bi-directional causality between the London and New York gold markets, and uni-directional causality from New York to the other markets. In this sense, the 
New York market has gained a leading role in affecting global gold markets. This empirical finding serves as a predictor for the gold price in global markets.

The second paper, entitled “A conditional single index model with local covariates for detecting and evaluating active management”, is by Massimiliano Caporin (“Marco Fanno” Department of Economics and Management, University of Padova, Italy) and Francesco Lisi (Department of Statistics, University of Padova, Italy), The intercept of standard Single Index and Conditional Single Index models, the so-called alpha, is often used to evaluate the long-run performance of managed portfolios. However, this measure is not always appropriate for detecting the presence and impact of active management strategies. Building on the conditional factor models literature, the authors introduce a Conditional Single Index model where the time-varying alpha and beta parameters depend only on the past history of the underlying portfolio returns and of the benchmark returns. The dynamics of the parameters have two components: the first describes the long-term behaviour of the alpha and beta, whereas the second is associated with the short-term performance of the underlying portfolio. The interpretation of the parameters allows the identification of portfolio managers who implement active management strategies. The paper provides an empirical application based on a large set of U.S. mutual funds showing the dispersion of active management approaches.

Michael McAleer (Econometric Institute, Erasmus School of Economics, Erasmus University Rotterdam, The Netherlands), Juan-Ángel Jiménez-Martín (Department of Quantitative Economics, Complutense University of Madrid, Spain), and Teodosio Pérez-Amaral (Department of Quantitative Economics, Complutense University of Madrid, Spain) answer the question given by "Has the Basel Accord improved risk management during the global financial crisis?” in the third paper. The Basel II Accord requires that banks and other Authorized Deposittaking Institutions (ADIs) communicate their daily risk forecasts to the appropriate monetary authorities at the beginning of each trading day, using one or more risk models to measure Value-at-Risk (VaR). The risk estimates of these models are used to determine capital requirements and associated capital costs of ADIs, depending in part on the number of previous violations, whereby realised losses exceed the estimated VaR. The authors define risk management in terms of choosing from a variety of risk models, and discuss the selection of 
optimal risk models. A new approach to model selection for predicting VaR is proposed, consisting of combining alternative risk models, and the paper compares conservative and aggressive strategies for choosing between VaR models. The authors then examine how different risk management strategies performed during the 2008-09 global financial crisis. These issues are illustrated using Standard and Poor’s 500 Composite Index.

In the fourth paper, “The role of banking regulation in an economy under credit risk and liquidity shock”, Marcos Soares da Silva (Central Bank of Brazil) and Jose Angelo Divino (Department of Economics, Catholic University of Brasilia, Brazil) develop a Dynamic Stochastic General Equilibrium model, which includes a financial sector to analyze the effects of a liquidity shock and credit risk in the Brazilian economy. Banks use equity capital and deposits from agents to finance investments of the production sector. The sources of financial frictions are possibility of default and liquidity shock, due to deposits withdrawn in advance. The banking supervisor injects liquidity in the financial market. The structural parameters of the model are estimated by Bayesian methods for the Brazilian economy using data for the period 1995 to 2009. Impulse response functions are computed to describe the dynamic effects of exogenous shocks. The major results of the paper show that credit risk is pro-cyclical and default risk depends on structural elements of the economy. The banking regulator is able to set up an optimal policy to promote financial stability and efficiently reduce fluctuations in the output.

Naoto Kunitomo (Faculty of Economics, University of Tokyo, Japan) and Seisho Sato (Institute of Statistical Mathematics, Tokyo, Japan) examine "Separating information maximum likelihood estimation of the integrated volatility and covariance with micro-market noise" in the fifth paper. For estimating the integrated volatility and covariance by using high frequency financial data, the authors propose the Separating Information Maximum Likelihood (SIML) method in the presence of micro-market noise. The resulting estimator, which is represented as a specific quadratic form of returns, is simple to implement. The paper shows that the SIML estimator has reasonable asymptotic properties, namely it is consistent and is asymptotically normal when the sample size is large, and the integrated volatility is deterministic under general conditions including some non-Gaussian processes and some volatility models. Based on simulations, the authors find that the SIML estimator has reasonable finite sample properties, which would make 
it useful for practice. The SIML estimator has the asymptotic robustness properties in the sense it is consistent when the noise terms are weakly dependent, and are endogenously correlated with the efficient market price process. The paper illustrates the use of SIML by analyzing Nikkei-225 Futures, which has been the major stock index in the Japanese financial sector.

In the sixth paper, namely "Stress testing correlation matrices for risk management”, Mike K.P. So (Hong Kong University of Science and Technology, Hong Kong), Jerry Wong (Hong Kong University of Science and Technology, Hong Kong), and Manabu Asai (Soka University, Japan) show that evaluating portfolio risk typically requires making correlation estimates of security returns. Historical financial events have shown that correlations can rise quickly, thereby causing a huge increase in portfolio risk. As such, in stress testing portfolios, it is important to consider the impact of a sudden surge in selected correlations. Standard correlation stress testing mechanisms lead to changes in selected correlations to designated values. However, the correlation matrix may become non-positive definite after some of its entries have been altered. The paper proposes a blocking method to convert an existing correlation matrix to incorporate the change, while keeping the matrix positive definite. Compared with existing methods which usually only achieve semi-positive definiteness, obvious out-performance is attained in the revised elements, while the approximation errors of the non-revised elements are maintained within acceptable levels. The simulations show that the proposed method is efficient and performs well for dimensions of 100, 500 and 1000 assets. It is also shown that the method is more reliable in stress testing higher-dimensional correlation matrices. The performance of the blocking method using a high-dimensional real data correlation matrix is also provided.

Chia-Chung Chan (Department of Finance, Tunghai University, Taiwan), Bing-Huei Lin (Department of Finance, National Chung Hsing University, Taiwan), Yung-Ho Chang (Department of Finance, Tunghai University, Taiwan), Wei-Chen Liao (Department of Finance, Tunghai University, Taiwan) answer the question, “Does bank relationship matter for corporate risk taking? Evidence from listed firms in Taiwan”, in the seventh paper. Single-bank or multiple-bank relationships can play a role in the degree of corporate risk taking that inspires financing decisions. The authors examine whether or not the magnitude of corporate risk taking 
is associated with bank relationship. They use public firms in Taiwan, with the sample period from 2001 to 2005, and select three variables based on earnings volatility and share price volatility as proxies for corporate risk-taking. The empirical evidence shows that multiple-bank relationships can lead firms to take greater risks under information asymmetry between banks and firms. The results remain unchanged even after considering the main-bank effect. Finally, the paper observes that firms with smaller size and higher growth opportunity tend to enhance the degree of corporate risk taking as they develop multiple-bank relationship.

In the eighth paper, Andrew C.Y. Ng (Department of Finance, CUHK, Hong Kong, China), Johnny S.H. Li (Department of Statistics \& Actuarial Science, University of Waterloo, Canada), and Wai-Sum Chan (Department of Finance, CUHK, Hong Kong, China) consider "Pricing options on stocks denominated in different currencies: Theory and illustrations". Basket options have long been an important structured product. It is possible to write a basket option on assets denominated in different currencies, but settle the option in one single currency at some fixed exchange rate. This special type of basket options can be found in many life insurance products that encompass an investment component. In order to value such options, we need to consider not only the joint dynamics of the returns on the underlying assets but also the quanto feature involved. The authors use a multivariate regime-switching geometric Brownian motion for modeling returns on various assets and exchange rates. As the parameters of the multivariate geometric Brownian motion can change according to the state of a Markov chain, the model allows for stochastic volatility and correlations. The paper demonstrates how domestic investors can choose a risk-neutral probability measure by the multivariate Esscher transform. This valuation methodology is illustrated with an hypothetical investment guarantee that is sold with a life insurance contract.

The ninth paper, "EVT and tail-risk modelling: Evidence from market indices and volatility series”, is by David E. Allen (School of Accounting Finance \& Economics, Edith Cowan University, Australia), Abhay K. Singh (School of Accounting Finance \& Economics, Edith Cowan University, Australia), and Robert J. Powell (School of Accounting Finance \& Economics, Edith Cowan University, Australia). Value-at-Risk (VaR) has become the universally accepted metric adopted internationally under the Basel Accord for banking industry 
internal control, capital adequacy and regulatory reporting. The recent extreme financial market events, such as the Global Financial Crisis (GFC) commencing in 2007 and the subsequent developments in European markets, mean there has been a great deal of attention paid to risk measurement, hedging, and associated derivatives. The techniques used to model tail risk, such as VaR, have attracted criticism for their inability to model extreme market conditions. The authors discuss tail-specific distribution-based Extreme Value Theory (EVT) and evaluate different methods that may be used to calculate VaR, ranging from well-known econometric models of GARCH and its variants to EVT-based models which focus specifically on the tails of the distribution. The paper applies univariate Extreme Value Theory to model extreme market risk for the FTSE100 UK Index and S\&P-500 US market indices, together with their volatility counterparts. The authors provide empirical evidence that EVT can be successfully applied to financial market return series for predicting static VaR, CVaR or Expected Shortfall (ES), and also daily VaR and ES using a GARCH(1,1) model and an EVT-based dynamic approach to these various indices. The behaviour of these indices in their tails has implications for hedging strategies in extreme market conditions.

John Garvey (Kemmy Business School, University of Limerick, Limerick, Ireland) and Liam A. Gallagher (Business School, Dublin City University, Dublin, Ireland) evaluate "The economics of data: Using simple model free volatility in a high frequency world" in the tenth paper. The paper examines the practical implications of using high frequency data in a fast and frugal manner, and recognises the continued widespread application of model free approaches within many trading and risk management functions. The analysis of the relative characteristics of four model-free volatility estimates is framed around their relative long memory effects, as measured by the feasible exact local Whittle estimator. For a cross-section of sixteen FTSE-100 stocks, for the period 1997-2007, the authors show that five-minute realized volatility exhibits a higher level of volatility persistence than approaches that use data in a sparse way (such as close-to-close volatility, high-low volatility, and Yang \& Zhang volatility). This observation is a useful decision tool for trading and risk management decisions that are undertaken in a timeconstrained task environment. The paper recommends that the use of sparse data (namely open, high, low and closing price observations) requires trader intuition and judgment to build longmemory effects into their pricing. 
The eleventh paper, “Arbitrage-free implied volatility surfaces for options on single stock futures”, is by Antonie Kotze (Financial Chaos Theory, South Africa), Coenraad C.A. Labuschagne (School of Computational and Applied Mathematics, University of the Witwatersrand, South Africa), Merell L. Nair (ABSA Capital, South Africa), and Nadine Padayachi (School of Computational and Applied Mathematics, University of the Witwatersrand, South Africa). The current method used by the Johannesburg Stock Exchange (JSE) to determine implied volatility is based on trade data and a linear deterministic approach. The paper constructs a market-related arbitrage-free implied volatility surface by using a quadratic deterministic function, for two stock indices and ten single stock futures. Actual traded data are used, and the authors show how all no-arbitrage conditions are implemented and tested in practice.

Chii-Shyan Kuo (Department of Accountancy, National Cheng Kung University, Taiwan) and Shih-Ti Yu (Department of Quantitative Finance, National Tsing Hua University, Taiwan) analyse "The non-uniform pricing effect of employee stock options using quantile regression” in the twelfth paper. Issuing employee stock options (ESOs) transfers equity claims from current stockholders to employees, and thereby dilutes existing shareholders' interests. As employees are motivated to exert additional efforts towards better performance, the value of transferred ownership claims proxied by ESO expense represents a cost of generating firm value. There are several econometric issues to be considered, notably that the disclosed ESO expense is an endogenous variable. Without controlling for the simultaneity problem, inferences based on results from OLS analyses may be misleading. Moreover, granting options to employees comprises operating and financing activities. These corporate finance decisions are not usually made at random, but are deliberate decisions made by managers to self-select their preferred choices. Econometric analysis which does not account for self-selection bias will lead to biased estimates and distorted statistical inferences. More importantly, a considerable amount of ESO expense data is censored at zero. Such a censoring problem can make the population distribution severely skewed, resulting in estimation bias. Therefore, it is essential to take into account the censored data issue. No prior studies have considered these three issues simultaneously. Failure to control for both self-selection bias and endogeneity could explain the inconsistent results documented in prior studies. The authors use quantile regression (QR) to examine possible 
nonlinear relationships, especially whether conditionally higher-stock price (or better performing) firms show a stronger negative pricing effect of ESO (that is, the relation between ESO expense and share price) than conditionally lower-share price firms. It is suggested that the results show the linear regression model greatly underestimates this negative pricing effect at higher quantiles, so that the non-linear relationship is obscure when using the standard linear model. The paper also considers alternative interpretations as to why heterogeneity in the pricing effect of ESO expense, and assesses whether the results concur with these explanations.

The thirteenth paper, "Nonlinear dynamics and recurrence plots for detecting financial crisis", is by Peter Martey Addo (European Doctorate in Economics, Erasmus Mundus (EDEEM), Centre d’Economie, University Paris I, Panthéon Sorbonne, France), Monica Billio (Department of Economics, Ca' Foscari University of Venice, Italy), and Dominique Guegan (Centre d'Economie, University Paris I, Panthéon Sorbonne, Ecole d'Economie de Paris, Paris School of Economics, France). The identification of financial bubbles and crises is a topic of major concern since it is important to prevent collapses that can severely impact nations and economies. The paper deals with the use of the recently proposed 'delay vector variance' (DVV) method, which examines local predictability of a signal in the phase space to detect the presence of determinism and nonlinearity in a time series. The optimal embedding parameters used in the DVV analysis are obtained via a differential entropy-based method using wavelet-based surrogates. The authors exploit the concept of recurrence plots to examine the stock market to locate hidden patterns and non-stationarity, and to examine the nature of these plots in financial crises. In particular, the recurrence plots are used to detect and characterize financial cycles. A comprehensive analysis of the feasibility of this approach is provided. The paper shows that the proposed methodology is useful in the diagnosis and detection of financial bubbles, which have significantly impacted economic upheavals in the past few decades.

Kin-Yip Ho (Research School of Finance, Actuarial Studies and Applied Statistics, Australian National University, Australia), Yanlin Shi (Research School of Finance, Actuarial Studies and Applied Statistics, Australian National University, Australia), and Zhaoyong Zhang (School of Accounting, Finance \& Economics, Edith Cowan University, Australia) answer the question given by "How does news sentiment impact asset volatility? Evidence from long memory and 
regime-switching approaches”, in the fourteenth paper. The paper examines the dynamic relationship between firm-level return volatility and public news sentiment. By using the new RavenPack Dow Jones Newswire database that measures over 300 types of firm-specific news releases and their sentiment scores at high frequencies, the authors investigate the circumstances in which public news sentiment is related to the intraday volatility of the individual stocks in the Dow Jones Composite Average. They develop a two-state Markov Regime-Switching GARCH model with long-memory persistence in volatility, and the results confirm the significant impact of firm-specific news sentiment on overall volatility. In particular, it is observed that news sentiment accounts for a greater proportion of volatility persistence in the low-volatility regime ("calm" state) than in the high-volatility regime ("turbulent" state). Furthermore, in the calm state, negative news sentiment has a greater impact on volatility compared with positive news sentiment. However, this asymmetric effect between positive and negative news sentiment is insignificant in the turbulent state. Moreover, the impact of news sentiment differs across industrial sectors and firm size. Two different conditionally heteroskedastic models are used, namely the Fractionally Integrated Generalized Autoregressive Conditionally Heteroskedastic (FIGARCH) and the two-state Markov Regime-Switching GARCH (RS-GARCH) models. For most of the DJN 65 stocks, the results confirm the significant impact of firm-specific news sentiment on intraday volatility persistence, even after controlling for the potential effects of macroeconomic news. Compared with macroeconomic news sentiment, firm-specific news sentiment apparently accounts for a greater proportion of overall volatility persistence. Moreover, negative news has a greater impact on volatility than positive news. Furthermore, the results from the RS-GARCH model indicate that news sentiment accounts for a greater proportion of volatility persistence in the high-volatility regime (turbulent state) than in the low-volatility regime (calm state). In-sample forecasting performance and residual diagnostic tests suggest that FIGARCH generally outperforms RS-GARCH.

The fifteenth paper, "Quantitative evaluation of contingent capital and its applications", is by Anshul Gupta (Nomura Securities, Japan), Toshinao Akuzawa (Nomura Securities, Japan), and Yoshihiko Nishiyama (Institute of Economic Research, Kyoto University, Japan). A new type of regulatory capital for banks, known as contingent capital, has emerged in tandem with discussions on the Basel III regulatory framework, but there is a lack of consensus on a standard 
valuation approach among those proposed so far. The authors argue that the practical solution is to be able to price these instruments seamlessly and consistently with other existing derivatives. They propose a novel and practical “convertible bond approach", which is theoretically consistent with existing frameworks such as Black-Scholes, and is conceptually and technically similar to the pricing models already in use for convertible bonds and hybrid securities. Such a model is reasonable as all of these asset classes are hybrid equity-credit instruments and share many characteristics. Moreover, contingent capital, through its unique mechanisms, such as principal loss absorption, presents interesting risk scenarios which may not be readily apparent or may appear counterintuitive. Contingent capital may, at first sight, appear to carry obscure risks, but the authors show that, by taking a careful quantitative approach, it is possible to understand the characteristics of such instruments in a concise manner. Furthermore, for discussing pricing in terms of characteristics of the issuer, one needs a concise framework to describe those characteristics in terms of Common Equity Tier 1 (CET1) ratio risk. The framework describes CET1 ratio risk via three intuitive issuer parameters, namely target, volatility, and resilience. In spite of the exotic risks, an investment decision in contingent capital can be justified if a sufficient return is expected in compensation. The paper presents a valuation method based on hurdle Sharpe ratios that has direct implications for investment decision making in the context of an expansion of the investor's efficient frontier. It is also demonstrated that the framework is useful as a daily pricing tool for market participants using empirical market data.

"High quantiles estimation with Quasi-PORT and DPOT: An application to value-at-risk for financial variables”, by Paulo Araujo Santos (Instituto Politecnico de Santarem and CEAUL, Portugal), Isabel Fraga Alves (Universidade de Lisboa and CEAUL, Portugal), and Shawkat Hammoudeh (Lebow College of Business, Drexel University, PA, USA), is the sixteenth paper. Recurrent "black swans" financial events are a major concern for both investors and regulators because of the extreme price changes they cause, despite their very low probability of occurrence. The paper uses unconditional and conditional methods, such as the high quantile (HQ) extreme value theory (EVT) models of DPOT (Duration-based Peak over Threshold) and quasi-PORT (Peaks Over Random Threshold), to estimate the Value-at-Risk with very small probability values for adequately long financial time series to obtain a reasonable number of violations for backtesting. These models and other alternative strategies are compared through an out-of- 
sample accuracy investigation to determine their relative performance within the HQ context. Policy implications relevant to estimation of risk for extreme events are also provided.

The seventeenth paper, "Evaluating inflation targeting based on the distribution of inflation and inflation volatility”, is by Mzwandile Ginindza (Department of Economics, Emory University, USA) and Esfandiar Maasoumi (Department of Economics, Emory University, USA). The Financial Development Index (FDI) is used to rank 57 of the world's leading financial systems. Its calculation is based on the following seven economic pillars: (1) Institutional environment, (2) Business environment, (3) Financial stability, (4) Banking financial services, (5) Non-banking financial services, (6) Financial markets, and (7) Financial access. Pillar (4) is constructed from bond markets, stock markets, foreign exchange markets, and derivative markets. Pillar (5) includes a country's IPO activity, namely the IPO market share, IPO proceeds, and IPO's share of world IPOs. The stock market index provides a short-term account of financial activities, whereas the FDI provides a long-term broader account of the financial structure and health of an economy. As the performance and success of a given monetary policy would less likely be judged on short-term dynamics, it seems sensible to use the annual FDI as one of several economic and country attributes in a policy evaluation of Inflation Targeting. The paper offers a potential outcomes analysis of the impact of inflation targeting on inflation and inflation volatility, and focuses on advanced economies that adopt "inflation targeting" as a formal monetary policy. In order to deal with the counterfactual question, namely what would be the inflation rate for an adopting country had it not adopted this policy, the paper offers a new matching technique that subsumes the traditional Propensity Scores methods as a special case. The paper has different proposals for assessing "matching" based on the whole distribution of any "scores". Additionally, the paper goes beyond the Average Treatment Effect (ATE) and examines the entire distribution of inflation and its volatility. It is found that the adoption of Inflation Targeting has helped lower inflation (not just the mean) for the targeting countries. However, it is shown that exact numerical quantification of this policy effect is as highly subjective as choosing ideal social welfare functions. The paper also finds no evidence of a larger gain for "late adopters" of inflation targeting. As for inflation volatility, there is some robust evidence of small and often statistically insignificant reduction in volatility due to targeting. 
Chia-Lin Chang (National Chung Hsing University, Taiwan), Hui-Kuang Hsu (National Pingtung Institute of Commerce, Taiwan), and Michael McAleer (Econometric Institute, Erasmus School of Economics, Erasmus University Rotterdam, The Netherlands) answer the question given by "Is small beautiful? Size effects of volatility spillovers for firm performance and exchange rates in tourism” in the eighteenth paper. This paper examines the size effects of volatility spillovers for firm performance and exchange rates with asymmetry in the Taiwan tourism industry. The analysis is based on two conditional multivariate models, BEKKAGARCH and VARMA-AGARCH, in the volatility specification. Daily data from 1 July 2008 to 29 June 2012 for 999 firms are used, which covers the Global Financial Crisis. The empirical findings indicate that there are size effects on volatility spillovers from the exchange rate to firm performance. Specifically, the risk for firm size has different effects from the three leading tourism sources to Taiwan, namely USA, Japan, and China. Furthermore, all the return series reveal quite high volatility spillovers (at over sixty percent) with a one-period lag. The empirical results show a negative correlation between exchange rate returns and stock returns. However, the asymmetric effect of the shock is ambiguous, owing to conflicts in the significance and signs of the asymmetry effect in the two estimated multivariate GARCH models. The empirical findings provide financial managers with a better understanding of how firm size is related to financial performance, risk and portfolio management strategies that can be used in practice.

In the nineteenth paper, Karim Bannouh (Econometric Institute, Erasmus University Rotterdam, The Netherlands), Martin Martens (Department of Finance, Erasmus University Rotterdam, The Netherlands) and Dick van Dijk (Econometric Institute, Erasmus University Rotterdam, The Netherlands) evaluate "Forecasting volatility with the realized range in the presence of noise and non-trading”. The paper introduces a heuristic bias-adjustment for the transaction price-based realized range estimator of daily volatility in the presence of bid-ask bounce and non-trading. The authors relax the assumption that all intra-day high (low) transaction prices are at the ask (bid) quote. Using data-based simulations, they obtain estimates of the probability that a given intra-day range might be (upward or downward) biased to obtain a more refined bias-adjustment of the realized range estimator. Both Monte Carlo simulations and an empirical application involving liquid and relatively illiquid S\&P500 constituents demonstrate that ex post measures 
and ex ante forecasts based on the heuristically adjusted realized range compare favourably to existing bias-adjusted (two time scales) realized range and (two time scales) realized variance estimators.

Chor-Yiu (CY) Sin (Department of Economics, National Tsing Hua University, Taiwan) examines "Using CARRX models to study factors affecting the volatilities of Asian equity markets" in the twentieth paper. The range of daily asset prices is often used as a measure of volatility. Using a CARRX (conditional autoregressive range with exogenous variables) model, and the parsimony principle, the paper investigates the factors affecting the volatilities of Asian equity markets. Since the beginning of the new Century, emerging Asian markets such as Taiwan and Shanghai have been undergoing various stages of financial globalization. The volatility of the equity market may not be explained solely by its own dynamics. The paper examines volatility using the following factors: (i) lagged returns; (ii) lagged absolute returns; (iii) own trading volume; (iv) U.S. factors; (v) European factors; and (vi) regional (Asian) factors. Points (i) and (iii) are by and large significant, while (ii) is not. Controlling for (i), (ii) and (iii), the paper finds evidence that the volatility of European markets has spillovers on to both the Taiwan and Tokyo markets, and mild evidence that the volatility of the U.S. market has spillovers on to the Hong Kong market. However, no spillovers are found from the European or U.S. markets on to the Shanghai market.

In the twenty-first paper, Loriana Pelizzon (Department of Economics, Ca' Foscari University of Venice, Italy) and Domenico Sartore (Department of Economics, Ca' Foscari University of Venice, Italy) analyse aspects of "Deciphering the Libor and Euribor spreads during the subprime crisis”. The paper investigates the key role played by different factors, such as the use of Asset Backed Commercial Paper as collaterals in the short-term debt market, credit risk and the injection of liquidity by Central Banks through so-called unconventional measures, on the persistent spread during the subprime crisis bet. The empirical analysis shows that, in addition to credit risk, a relevant variable for explaining the interbank rate dynamics is the outstanding volume in the Asset Backed Commercial Paper market. In summary, the large spread observed in the market is explained by the inter-relationship between collateralized short-term debt markets 
and the unsecured interbank market. It is also shown that ECB intervention variables affect the spread mainly in the short run.

Alan T. Wang (Department of Accounting \& Graduate Institute of Finance, National Cheng Kung University, Taiwan), Sheng-Yung Yang (Department of Finance, National Chung Hsing University, Taiwan), and Nien-Tzu Yang (Department of Finance, National Chung Hsing University, Taiwan) investigate "Information transmission between sovereign debt CDS and other financial factors: The case of Latin America” in the twenty-second paper. The paper extends previous research by investigating the intertemporal causality relationships between daily Latin America sovereign credit default swap (CDS) returns and other financial sovereign debt spread determinants. The empirical results indicate that information in sovereign CDS can both lead and lag these financial determinants. Specifically, country financial variables, including exchange rates and lending spreads, and global financial variables including 10-year U.S. Treasury yields, VIX and TED spreads, are important determinants for future sovereign CDS price movements. The empirical findings provide investment implications for international financial markets.

In the penultimate and twenty-third paper, Markus Haas (Institute for Quantitative Business and Economics Research, University of Kiel, Germany), Jochen Krause (Department of Banking and Finance, University of Zurich, Switzerland), Marc S. Paolella (Department of Banking and Finance, University of Zurich, Switzerland), and Sven C. Steude (Department of Banking and Finance, University of Zurich, Switzerland) extend the literature in "Time-varying mixture GARCH models and asymmetric volatility”. The authors argue that the class of mixed normal conditional heteroskedastic (MixN-GARCH) models, which couples a mixed normal distributional structure with GARCH-type dynamics, has been shown to offer a plausible decomposition of the contributions to volatility, as well as an excellent out-of-sample forecasting performance, for financial asset returns. The paper generalizes the MixN-GARCH model by relaxing the assumption of constant mixing weights. Two different specifications with timevarying mixing weights are considered. In particular, by relating current weights to past returns and realized (component-wise) likelihood values, an empirically reasonable representation of Engle and Ng's (1993) news impact curve with an asymmetric impact of unexpected return 
shocks on future volatility is obtained in the paper. An empirical out-of-sample study confirms the usefulness of the new approach and gives evidence that the leverage effect in financial returns data is closely connected, in a non-linear manner, to the time-varying interplay of mixture components representing, for example, various groups of market participants.

Shiqing Ling (Department of Mathematics, Hong Kong University of Science and Technology, Hong Kong), Ke Zhu (Department of Mathematics, Hong Kong University of Science and Technology, Hong Kong), and Chong Ching Yee (Department of Mathematics, Hong Kong University of Science and Technology, Hong Kong) develop novel testing methods in "Diagnostic checking for non-stationary ARMA models with an application to financial data" in the twenty-fourth and final paper. The paper derives the limiting distributions of the residual and squared residual autocorrelation functions of the nonstationary autoregressive moving average model. The authors use the two autocorrelation functions to construct two portmanteau statistics for testing the adequacy of the fitted time series model. Simulation results show that the tests have reasonable empirical sizes and powers in finite samples. Finally, the paper uses daily SP500 data to illustrate the usefulness of the theory and approach in practice.

\section{Final Remarks}

We hope that the interesting and innovative papers in this special issue by some of the leading experts in financial economics and financial econometrics will be of wide interest to both theoreticians and practitioners, and will encourage further research in the advanced and challenging areas that are expanding rapidly in financial economics and financial econometrics.

It is our pleasure to acknowledge all the contributors to the special issue for preparing their interesting, exciting and innovative papers in a timely manner. It is also a pleasure to acknowledge the referees for their timely and helpful comments and suggestions on the papers comprising the special issue. 


\section{References}

Addo, P.M., M. Billio and D. Guegan (2013), "Nonlinear Dynamics and Recurrence Plots for Detecting Financial Crisis”, to appear in North American Journal of Economics and Finance, this issue.

Allen, D.E., A.K. Singh and R.J. Powell (2013), "EVT and Tail-risk Modellilng: Evidence from Market Indices and Volatility Series”, to appear in North American Journal of Economics and Finance, this issue.

Araujo Santos, P., I. Fraga Alves and S. Hammoudeh (2013), "High Quantiles Estimation with Quasi-PORT and DPOT: An Application to Value-at-Risk for Financial Variables”, to appear in North American Journal of Economics and Finance, this issue.

Bannouh, K., M. Martens and D. van Dijk (2013), "Forecasting Volatility with the Realized Range in the Presence of Noise and Non-trading", to appear in North American Journal of Economics and Finance, this issue.

Caporin, M. and F. Lisi (2013), “A Conditional Single Index Model with Local Covariates for Detecting and Evaluating Active Management”, to appear in North American Journal of Economics and Finance, this issue.

Chan, C.-C., B.-H. Lin, Y.-H. Chang and W.-C. Liao (2013), “Does Bank Relationship Matter for Corporate Risk Taking? Evidence from Listed Firms in Taiwan”, to appear in North American Journal of Economics and Finance, this issue.

Chang, C.-L., J.-C. Chang, Y.W. Huang (2013), “Dynamic Price Integration in the Global Gold Market”, to appear in North American Journal of Economics and Finance, this issue. 
Chang, C.-L., H.-K. Hsu and M. McAleer (2013), Is Small Beautiful? Size Effects of Volatility Spillovers for Firm Performance and Exchange Rates in Tourism”, to appear in North American Journal of Economics and Finance, this issue.

Garvey, J. and L.A. Gallagher (2013), "The Economics of Data: Using Simple Model Free Volatility in a High Frequency World”, to appear in North American Journal of Economics and Finance, this issue.

Ginindza, M. and E. Maasoumi (2013), "Evaluating Inflation Targeting Based on the Distribution of Inflation and Inflation Volatility”, to appear in North American Journal of Economics and Finance, this issue.

Gupta, A., T. Akuzawa and Y. Nishiyama (2013), "Quantitative Evaluation of Contingent Capital and its Applications”, to appear in North American Journal of Economics and Finance, this issue.

Haas, M., J. Krause, M.S. Paolella and S.C. Steude (2013), "Time-varying Mixture GARCH Models and Asymmetric Volatility", to appear in North American Journal of Economics and Finance, this issue.

Ho, K.-Y., Y. Shi and Z. Zhang (2013), "How Does News Sentiment Impact Asset Volatility? Evidence from Long Memory and Regime-switching Approaches”, to a ppear in North American Journal of Economics and Finance, this issue.

Kotze, A., C.C.A. Labuschagne, M.L. Nair and N. Padayachi (2013), "Arbitrage-free Implied Volatility Surfaces for Options on Single Stock Futures”, to appear in North American Journal of Economics and Finance, this issue.

Kunitomo, N. and S. Sato (2013), "Separating Information Maximum Likelihood Estimation of the Integrated Volatility and Covariance with Micro-market Noise”, to appear in North American Journal of Economics and Finance, this issue. 
Kuo, C.-S. and S.-T. Yu (2013), “The Non-uniform Pricing Effect of Employee Stock Options Using Quantile Regression”, to appear in North American Journal of Economics and Finance, this issue.

Ling, S., K. Zhu and C.C. yee (2013), “Diagnostic checking for non-stationary ARMA models with an application to financial data”, to appear in North American Journal of Economics and Finance, this issue.

McAleer, M., J.-A. Jiménez-Martín and T. Pérez-Amaral (2013), “Has the Basel Accord improved risk management during the global financial crisis?”, to appear in North American Journal of Economics and Finance, this issue.

Ng, A.C.Y., J.S.H. Li and W.-S. Chan (2013), "Pricing Options on Stocks Denominated in Different Currencies: Theory and Illustrations”, to appear in North American Journal of Economics and Finance, this issue.

Pelizzon, L. and D. Sartore (2013), “Deciphering the Libor and Euribor Spreads During the Subprime Crisis”, to appear in North American Journal of Economics and Finance, this issue.

So, M.K.P., J. Wong and M. Asai (2013), "Stress Testing Correlation Matrices for Risk Management”, to appear in North American Journal of Economics and Finance, this issue.

Soares da Silva, M. and J.A. Divino (2013), “The Role of Banking Regulation in an Economy Under Credit Risk and Liquidity Shock”, to appear in North American Journal of Economics and Finance, this issue.

Wang, A.T., S.-Y. Yang and N.-T. Yang (2013), "Information transmission between sovereign debt CDS and other financial factors: The case of Latin America”, to appear in North American Journal of Economics and Finance, this issue. 